\title{
Professor José Luís Costa Lima, with an extensive and prestigious academic career, collaborated and continues to collaborate with many Brazilian research groups
}

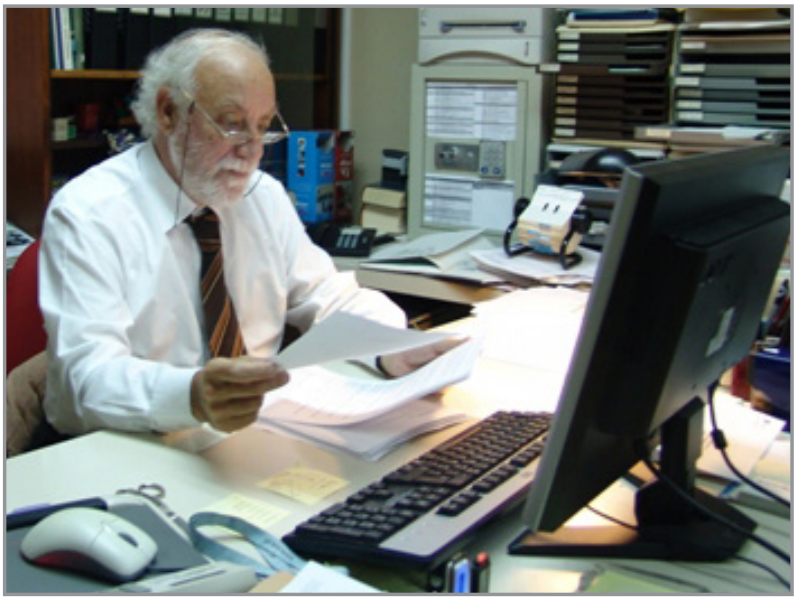

José Luís Costa Lima

Emeritus Professor

Faculty of Pharmacy, University of Porto, Portugal limajlfc@ff.up.pt

Professor José Luís Costa Lima was born in Cidade do Porto, Portugal, and graduated in Chemistry at the Faculty of Sciences of the University of Porto, where he also obtained a PhD degree with a thesis titled "Ion-selective electrodes with conductive resin support". In 1986, he joined the Faculty of Pharmacy of the University of Porto (FFUP) as an assistant professor and participated in the founding of a group in the area of Analytical and Applied Chemistry that resulted in the creation of a true "School of Analytical Chemistry", generating more than 40 PhDs, whom Professor Costa Lima affectionately calls "scientific children". In 1992, he began to work as an associate professor at FFUP and in 1996 as full professor. On December 4, 2015 he gave his last lecture at the Noble Hall of the Abel Salazar Institute of Biomedical Sciences (ICBAS) / FFUP complex.

Throughout his academic career in the Faculty of Pharmacy, Costa Lima has advised several PhD students in exchange programs with Spanish and Brazilian universities. He was responsible for the disciplines of "Analytical Chemistry and Instrumental Methods of Analysis", "Chemical and Physical Control" and "Methods of Analysis in Analytical Toxicology" at undergraduate and postgraduate levels from 2009 to 2015. He has held several management positions: as Chairman of the Board of Directors (1998-1999), President of the Scientific Council (20002001) and Director of the Faculty of Pharmacy (2011-2015). Outside the University of Porto, he collaborated with the Superior School of Biotechnology of the Catholic University, Porto, Portugal, where he was responsible for the discipline of Analytical Chemistry and Instrumental Methods (1985-2011). He was president of the Institute of Agrarian Sciences and Technologies and Agrifood (1998-2012) and member of the Scientific and Technical Committee of REQUIMTE (Network of Chemistry and Technology), Associated Laboratory for Green Chemistry (20012008), all in Portugal. He was the coordinator and executive investigator of more than four dozen research projects on the automation of chemical and biochemical analyses. He developed, with the collaboration of Professors Elias Zagatto and Boaventura Freire dos Reis, both from the University of São Paulo (Brazil), the multiple switching in flow networks by multiswitch and multi-impulsion, two automation techniques based on conditions of chemical non-equilibrium 
at the time of execution of the analytical measurements. These techniques were then used internationally in the development of new analytical methods.

Professor Costa Lima is the author or co-author of more than $\mathbf{5 0 0}$ scientific papers published in more than 100 Portuguese and foreign journals, in the areas of Fundamental Analytical Chemistry, and Food, Biological and Environmental Control Analytical Chemistry. He has made more than 1000 communications at national and international congresses, and his $h$ index (ISI) equals 45 with over 16,500 citations. In 2016, he was honored by the Division of Analytical Chemistry of the Brazilian Chemical Society, in recognition of his contribution to teaching and research. In March 2017, in the commemorations of the University of Porto Day, he was distinguished with the title of Professor Emeritus of the University of Porto. Since 2005, Professor Costa Lima has been a foreign member of the Brazilian Academy of Sciences and of numerous other scientific societies, such as the Portuguese Society of Chemistry (vice-president, 2004-2006; president of the Division of Analytical Chemistry, 1996-1998 and 2000-2003; and president of the "Porto" Delegation, 2007-2012), the Portuguese Society of Electrochemistry, the Spanish Society of Analytical Chemistry, and the International Society of Electrochemistry. He was also president of the Portuguese Society of Pharmaceutical Sciences (2010-2015) and the Portuguese Society of Electrochemistry (2000-2002).

Which factors influenced your education? What motivates you in analytical chemistry?

Throughout my school education, a set of facts that led me to Analytical Chemistry came together. My entrance to the university, with facilities that do not exist today, has resulted from an occasional choice for the Chemical Sciences. In my undergraduate course, the final term paper that was assigned to me (at the time the students' choices were not considered) was an analytical application of electrochemistry, which contributed decisively to consolidate my connection with Analytical Chemistry.

What are your lines of research? What work are you currently developing?

In Portugal, a large part of the research management and funding structure occurs in parallel with the university teaching career. Thus, it was possible for me to maintain the links with the Research Center to which I have always belonged, so that I maintain the same lines of research that I followed before my retirement. Recently, the

"the execution of a project funded by the European Space Agency has further aroused my interest in chemistry and analytical instrumentation in the absence of gravity"... execution of a project funded by the European Space Agency has further aroused my interest in chemistry and analytical instrumentation in the absence of gravity.

Do you keep informed about the progress of chemistry research? What is your opinion about the current progress of research in chemistry in the Ibero-American region? What are the latest advances and challenges in instrumentation for flow injection analysis?

As I have already mentioned, my research activity has not significantly changed in recent years, which leads me to systematically follow the enormous growth of chemistry research in the lbero-American region. It should, however, be emphasized that it could be even more significant if collaboration between the various countries of the region were encouraged in some way.

Concerning the second part of the question, I think it is difficult to find significant instrumental advances related to Flow Injection Analysis, except those concerning miniaturization. From the strategic point of view, it is worth noting the rupture with the original and traditional concept of a laminar flow-based transport in favor of the advantageous alternative of the use of pulsed flows. 
For you, what have been the most important achievements in the analytical research field recently? What were the landmarks? What are the latest advances and challenges in analytical chemistry?

"From my point of view, the most important achievements in the analytical field is the increasing democratization of the use of instrumentation".

It is tempting and easy to answer the formulated question referring to the advent or refinement of analytical techniques that have allowed reductions in the limits of detection and increases in the selectivity of the methods. From my point of view, the most important achievements in the analytical field is the increasing democratization of the use of instrumentation; that is, the ease of access to equipment, both in teaching and scientific research, and even in companies, compared to the existing situation in the last 20 years. In addition to this achievement, miniaturization has enabled the individual use of equipment to monitor relevant parameters of the health status of its bearer.

There are several meetings of chemistry experts that take place around the world. Last year, for example, the $19^{\text {th }}$ Brazilian Meeting on Analytical Chemistry (ENQA) and $7^{\text {th }}$ Ibero-American Congress on Analytical Chemistry (CIAQA) focused on Innovation for Sustainable Analytical Chemistry. What is the importance of these meetings to the development of the area?

My response is supported by my participation in all ENQAs over the past 30 years as well as in the seven CIAQAs that have already taken place. My presence at these events allowed me to note that the ongoing research in Latin America and the growing participation of young researchers are very significant, but the same growth has not been detected with regard to collaborative work among institutions in the same country or among institutions in different countries. Particularly in the case of the CIAQA, it is necessary for the societies involved in its organization to be more active in creating conditions for the movement and participation of its members in the congress, and it is urgent that, at the central level, projects are implemented to increase the internationalization of research.

Currently, you are an Emeritus Professor at the Faculty of Pharmacy at the University of Porto. In addition, do you perform other jobs? How many scientific papers have you published and can you share any highlights with us?

As I have already mentioned, my connection with research has not changed significantly in recent years, since I remain full time and exclusively dedicated to the Faculty of Pharmacy at the University of Porto and consequently do not have any additional job. My research activity developed so far has resulted in more than 518 indexed articles that originated more than 16,500 citations. I cannot fail to point out that, among these works, 89 were published with groups from Brazil, reflecting partnerships of colleagues in Brazilian cities such as João Pessoa, Recife, Salvador, São Carlos, Campinas, Araraquara, São Paulo and especially Piracicaba, where I established a fantastic partnership and friendship with Professor Elias Zagatto and colleagues. It all started at a congress held in Cordoba (Spain) in 1989, where we assumed the commitment to start a collaboration between Brazil and Portugal in the field of analytical chemistry, a commitment that was always cherished by Professor Henrique Bergamin Filho until his death.

What sort of a career could someone expect in the field of analytical chemistry? What advice would you give to a newcomer to this area?

The speed of technological evolution recommends moderation in the predictions that can be made regarding any activity. I would stress, however, that given the nature and areas of intervention of analytical chemistry, it will always need specialists who respond to society's growing concerns in areas such as food safety and environmental control, as well as public health. Such a scenario assures newcomers good perspectives and a lot of work, whether they face their future activity in teaching, 
research or control, or whether they work in public or private entities.

Do you believe that the current graduate programs produce quality researchers in the field of analytical chemistry? Is there need for further integration?

My knowledge of undergraduate and postgraduate programs that I have been able to follow in Brazil over the past 30 years shows that the evolution was remarkable, with an ever-growing number of excellent and committed students who, in most cases, can be recommended as candidates for the highlevel postgraduate courses that many universities offer. With regard to this last aspect, I should point out that it is desirable that the training system assign greater importance to the tutorial role of supervisors.

For you, what is the importance of the support of funding agencies for the scientific development of the country?

As is usual to say (and governments are well aware), research spending is not an expense but an investment. However, in all countries, there is a tendency to lament the supposedly small volume of investment mobilized by the funding agencies, and Brazil is no exception. However, as an external observer, it seems to me that there are aspects that significantly affect the profitability of the financial resources made available. Managers of science and technology who simplify the execution of the projects, along with agile ways of acquiring the required means for the development of the programs would be very significant improvements and would be advantageous alternatives to the injection of larger funds.

You have also received some awards in more than one category. What is it like to receive this recognition? What is the importance of these awards in the development of new technologies?

In fact, throughout my career, I was honored with certain awards, such as the Galician-Portuguese Chemistry Prize awarded by the National Association of Chemists of Spain (1991), the Prize for Excellence in Research by the Foundation for Science and Technology (2004), the FIA Honor Award for Science by the Japanese Association for Flow Injection Analysis (2008), the Ferreira da Silva Prize (career award) and as Honorary Member of the Portuguese Chemical Society (2012 and 2016). These awards were a great satisfaction to me and correspond to peer recognition, but I must point out that my greatest personal satisfaction resulted in being a foreign member of the Brazilian Academy of Sciences (2015). 